\title{
STUDY OF THE COMPETITIVENESS OF POLISH FOREIGN TRADE USING THE AUGMENTED GLEJSER, GOOSSENS AND VAN DEN EEDE METHOD
}

This paper proposes a modified version of the Glejser, Goossens and van den Eede method of testing the intensity of intra-industry foreign trade (1982). The original method was not equipped with adequate statistical and econometric instrumentation, which markedly reduced its practical utility. The paper proposes a study of the dynamics, direction of change and co-integration of the time-series of the Glejser, Goossens and van den Eede indicators. This kind of test procedure has been used to study the competitiveness of Poland's foreign trade in four groups of products of different levels of technological advancement. The findings show that the Polish economy has an increasing ability to sell goods with a slight technological advancement, whereas its competitiveness in high-tech goods is poor.

Keywords: Glejser index, intra-industry trade, time series, cointegration

JEL Classifications: F14

DOI: $10.15611 /$ aoe.2018.1.07

\section{INTRODUCTION}

The intensification of intra-industry trade in the modern world can be considered to be a determinant of the international competitiveness and openness of a country's economy. The growing importance of this kind of foreign trade has resulted in the development of various methods measuring the intensity and structure of intra-industry trade. They are mostly based on specially constructed indicators reflecting the size of intra-industry trade. One of the best known and most commonly used methods in business practice is the Grubel-Lloyd index (1975). Other noteworthy methods were proposed by Aquino (1978), Brülhart (1994), Greenaway, Hine and Milner (1995) and Fontagné, Freudenberg and Péridy (1997).

The emergence of ever newer metrics of intra-industry trade reflects the ongoing scientific discussion endeavouring to define and measure this very type of trade, at the same time the discussions reveal the shortcomings of the above indicators. Thus, for example, the Grubel-Lloyd index tends to

\footnotetext{
* Department of Statistics, Cracow University of Economics.
} 
understate the importance of intra-industry trade at times of trade imbalances, while the construction of the Aquino index, in turn, assumes a uniform distribution of the balance of foreign trade between industries which, in practice, is not necessarily the case. In addition, Grubel-Lloyd and Aquino as well as Brülhart, do not allow one to distinguish between different types of intra-industry trade (such as vertical and horizontal intra-industry trade). On the other hand the application of the Greenaway, Hine and Milner or Fontagné, Freudenberg and Péridy indicators can generate problems arising, among others, from the absence of a unified unit of goods (the value of goods is per unit of weight, volume etc.). The various proposals for measuring the intensity of intra-industry trade also include the Glejser, Goossens and van den Eede procedure (1982), which will be discussed in this paper. It has not been widely used in empirical studies, most probably due to its having been insufficiently equipped with the statistical and econometric tools facilitating statistical inference and the generalisation of results.

The Glejser, Goossens and van den Eede method is based on indicators of export-oriented and import-oriented specialisation computed for individual industries and the economy as a whole. The essence of this concept involves the assumption that small variance values of these indicators are indicative of the growing importance of intra-industry trade. The authors did not, however, specify a clear-cut criterion by which to judge whether a variance can be considered small or not. Instead, they proposed investigating the significance of changes in the variation of indicators of export-oriented and import-oriented specialisation by means of the classic $F$ test for two variances. Although the proposed research tool seems to be insufficient especially if the basis for assessing changes in variances is based on a time series comprising markedly more than two observations (variances). Under these conditions, determining the direction of changes in variance over time and the intensity of these changes would seem to be a more appropriate procedure.

Therefore the author proposes to extend the Glejser, Goossens and van den Eede method so that it includes statistical and econometric tools. This will result, on the one hand, in producing a study of the development trend of the time series of export-oriented and import-oriented indicators by means of a trend function and, on the other, in testing the cointegration of these time series. This in turn will permit an assessment of both the direction of change, the dynamics of the time series and an identification of the convergence of export-oriented and import-oriented processes of speciali-sation in intra- 
industry trade. So modified, the Glejser, Goossens and van den Eede procedure will be applied to study the intensity of Poland's intra-industry trade in 2002-2014. In order to diagnose the economy's ability to compete internationally more broadly, the said method has been used for industries revealing varying degrees of technological advancement. The computations have been based on data accessed from Eurostat's electronic resources.

\section{METHOD OF STUDYING THE DYNAMICS AND INTENSITY DIRECTION OF INTRA-INDUSTRY TRADE}

The study of the intensity of intra-industry trade draws on the Glejser, Goossens and van den Eede procedure (1982). The procedure is based on the determination of the indicators of export-oriented and import-oriented specialisation of the individual industries of a given country (or group of countries). These indicators are calculated based on the following formulas:

$$
\begin{aligned}
& a_{i}=\log \left(\frac{X_{i}}{X}: \frac{X_{g i}}{X_{g}}\right), \\
& b_{i}=\log \left(\frac{M_{i}}{M}: \frac{M_{g i}}{M_{g}}\right),
\end{aligned}
$$

where:

$a_{i}$ - export intensity indicator of industry $i$,

$b_{i}-$ import intensity indicator of industry $i$,

$X$ - overall value of a studied country's exports (to the world market or a selected group of countries),

$X_{i}$ - value of a studied country's exports in industry $i$,

$X_{g i}$ - value of worldwide exports (or of a selected group of countries' exports) of industry $i$ to a selected country,

$X_{g}$ - value of worldwide exports (or of a selected group of countries' exports),

$M$ - overall value of a studied country's imports (on the global market or to a selected group of countries),

$M_{i}$ - value of a selected country's imports in industry $i$,

$M_{g i}$ - value of worldwide imports (or of a selected group of countries' imports) of industry $i$ to a selected country,

$M_{g}$ - value of overall worldwide imports (or of the imports of a selected group of countries). 
According to the Glejser, Goossens and van den Eede method, the intensity of intra-industry trade is not determined by the values of $a_{i}$ and $b_{i}$ alone, but by their variability measured in terms of variances. The variances of $a_{i}$ and $b_{i}$ indicators can be calculated as follows:

$$
\begin{gathered}
S_{a_{i}}^{2}=\frac{1}{n} \sum_{i=1}^{n}\left(a_{i}-\bar{a}\right)^{2}, \\
S_{b_{i}}^{2}=\frac{1}{n} \sum_{i=1}^{n}\left(b_{i}-\bar{b}\right)^{2},
\end{gathered}
$$

where:

$n$ - number of industries considered,

$\bar{a}$ - mean value of export intensity indicator of industries,

$\bar{b}$ - mean value of import intensity indicator of industries.

The variance values are calculated for a particular industry group separately for each period (years, months). In the study there were considered manufacturing industries classified according to their global technological intensity (Hatzichronoglou 1997). The structure of International Standard Industrial Classification (ISIC) includes sections, divisions, classes and individual categories (the type of products, economic activities) ${ }^{1}$. The lower the level of variances $S_{a_{i}}^{2}$ and $S_{b_{i}}^{2}$, the higher the level of a country's specialisation in intra-industry trade. The failure of the authors' method to name the appropriate statistical tool to study shifts in the levels of both types of variance in terms of dynamics is admittedly a certain drawback of this method used to measure the intensity of intra-industry trade. This paper presents a procedure that will help eliminate the drawback. This is based on a study of development trends shaping the variances of export-oriented and import-oriented intensity indicators of intra-industry trade on the one hand, and a study of the cointegration of the time series of the variance, on the other.

In order to isolate the development trend of time series $S_{a_{i}}^{2}$ and $S_{b_{i}}^{2}$, one can use analytical methods to determine the variance trend for both types of indicators. One should assume that declining and statistically significant trends indicate an increase in the level of specialisation in both exports and imports, i.e. an increase in the importance of bilateral intra-industry trade. Inconsistencies of these trends' directions (i.e. a falling and a rising trend) in turn could mean an increase in the significance of intra-industry trade, but

\footnotetext{
${ }^{1}$ Specific types of goods included in this study are listed on page 6 of this paper.
} 
only in terms of focus on either exportation or importation alone. Consistent and positive directions of development trends in the studied time series mean a decline in the importance of bilateral intra-industry trade. Naturally the choice of the type of the theoretical trend function will depend on the course of the time series. Preliminary empirical analysis of computed variances $S_{a_{i}}^{2}$ and $S_{b_{i}}^{2}$ indicates that in the time series comprised of annual observations, a parabolic trend prevails. Other econometric models were less fit to empirical data or their parameters were statistically insignificant. Therefore, the direction and dynamics of intensity of intra-industry foreign trade have been examined using a quadratic trend function (Zeliaś 1996):

$$
Y_{t}=\alpha_{0}+\alpha_{1} t+\alpha_{2} t^{2}+\varepsilon_{t},
$$

where:

$Y_{t}$ - dependent variable (variance of the trade specialisation indicator), $t$ - variable of time $(t=1,2, \ldots, n)$.

The direction of the change in variable $Y_{t}$ established on the basis of model (5) depends on the sign of parameter $\alpha_{2}$ and the position of the value of the theoretical peak of the parabola on the horizontal axis, computed by means of the trend function $\hat{y}_{t}=a_{0}+a_{1} t+a_{2} t^{2}$ (cf. Table 1). One of the quadratic trend functions is presented in Figure 1. This figure plots sample time series of export-oriented indicators with annual frequency data for the low-tech industry (LTEx) and the fitted parabolic trend.

Table 1

Directions of change in intensity of intra-industry trade on the basis of the parabolic trend function

\begin{tabular}{c|c|c}
\hline $\begin{array}{c}\text { Sign } \\
\text { of parameter } \boldsymbol{a}_{2}\end{array}$ & $\begin{array}{c}\text { Domain } \\
\text { of variable } \boldsymbol{t}\end{array}$ & $\begin{array}{c}\text { Variable } \\
\boldsymbol{Y}_{\boldsymbol{t}} \text { trend }\end{array}$ \\
\hline positive & $t<-\frac{a_{1}}{2 a_{0}}$ & falling \\
\hline positive & $t>-\frac{a_{1}}{2 a_{0}}$ & rising \\
\hline negative & $t<-\frac{a_{1}}{2 a_{0}}$ & rising \\
\hline negative & $t>-\frac{a_{1}}{2 a_{0}}$ & falling \\
\hline
\end{tabular}

Sources: author's own research based on Eurostat data. 
The dynamics of changes in variable $Y_{t}$ considered on the basis of model (5) is determined by the absolute value of parameter $\alpha_{2}$ assessment: the higher it is, the higher the rate of change, and vice versa. Analysis of the convergence of these processes significantly complements the analysis of the development trends of intra-industry trade specialisation processes. The theoretical aspect of the analysis in question will be described next in this paper.

\section{METHOD OF CONVERGENCE TESTING OF EXPORT-ORIENTED AND IMPORT-ORIENTED PROCESSES OF SPECIALISATION IN INTRA-INDUSTRY TRADE}

The similarity of the two time series can be analysed from the angle of the trend (when trends determined for the compared time series are not significantly different), or in terms of the strict course of the time series (when the differences between time series are approximately constant over time).

In the latter case, one can talk about the convergence of export-oriented and import-oriented specialisation of foreign trade. In a situation where the convergence is accompanied by a declining variance trend, we are dealing with a steady increase in the level of economic competitiveness in both the international and the domestic markets. External and internal competitiveness in the field of sales of goods and services should then grow steadily. The convergence of sufficiently high frequency data, in practice, is identified by testing the cointegration of the time series. This is also the approach presented in the paper.

The intensity of export-oriented and import-oriented intra-industry trade and the process of their convergence will be analysed for each of the industries of varying levels of technological advancement, namely for the high-tech, medium-high tech, medium-low-tech and low-tech sectors ${ }^{2}$. This will allow a better assessment of the ability of the economy as a whole to

\footnotetext{
${ }^{2}$ The industries correspond to the 1995 OECD classification of goods by technological intensity reflecting the level of R\&D investment. In accordance with that classification, the following four groups of goods are distinguished: -high-tech goods such as aircraft, electronic and optical equipment, pharmaceuticals, -medium-high tech goods such as motor vehicles and other means of transport, electrical equipment, chemical products; - medium-low tech goods such as metal, rubber and plastic products, non-metallic mineral products, ferrous metals, non-ferrous metals; - low-tech goods such as paper, textile and leather products, clothing, food, beverages, wood.
} 
compete internationally and further an assessment of the competitive position of individual industries of varying degrees of innovation. The convergence of the export-oriented and import-oriented specialisation processes will be examined using time series cointegration testing. Cointegrated time series are characterized by a common long-term growth path, and the difference between their values is approximately constant. In practice, cointegration occurs when time series are of the same order of integration ${ }^{3}$ (mostly first order) and when there exists their stationary linear combination. Therefore vector $\left[X_{t}, Y_{t}\right]$ whose each component is first-order integrated $\left(X_{i} \sim \mathrm{I}(1)\right.$ and $\left.Y_{f} \sim \mathrm{I}(1)\right)$, is said to be cointegrated if there is a vector $\beta$ called a cointegration vector in which $\left(Y_{t}-\beta X_{t}\right) \sim \mathrm{I}(0)$.

The assessment of cointegration most commonly relies on the EngleGranger procedure (1987) or the maximum eigenvalue test (Johansen 1991, 1992).

In this paper the authors applied the Engle-Granger method to identify the cointegration of the time series. It is a two-stage procedure connected with the Error Correction Model. When testing the cointegration of two integrated series of the same order (e.g. $X_{t} \sim I(1)$ and $Y_{t} \sim I(1)$ ), first a regression model describing the relationship between one variable and the other variable by means of the least squares method is estimated:

$$
Y_{t}=\beta_{0}+\beta_{1} X_{t}+e_{t} .
$$

The next step involves the calculation of residuals on the basis of the computed model (6) and testing of the stationarity of the residuals in this model. In order to examine the degree of integration of the residuals one can use the Dickey Fuller test (DF test) ${ }^{4}$. Then the following equation (Osińska 2007) becomes the basis for testing the null hypothesis suggesting that the residuals of model (6) are not stationary:

$$
\Delta e_{t}=\delta e_{t-1}+u_{t} .
$$

If there is autocorrelation of residuals, the augmented Dickey-Fuller test (test ADF) should be used. In this case, stationarity of residuals is checked by means of the following equation:

\footnotetext{
${ }^{3}$ The time series $X_{t}$ is referred to as a stationary one since once the differences of order $d$ have been computed it is converted to a stationary series. The integration of process $X_{t}$ of order $d$ are marked as follows: $X_{t} \sim \mathrm{I}(\mathrm{d})$.

${ }^{4}$ Examination of the degree of residuals integrity can also be carried out on the basis of the Rother tests, e.g. the KPSS test.
} 


$$
\Delta e_{t}=\delta e_{t-1}+\sum_{i=1}^{k} \Delta e_{t-i}+u_{t} .
$$

In the case of rejection of $\mathrm{H}_{0}: \delta=0$ it is claimed that the residual process is stationary, i.e. $\sim \mathrm{I}(0)$. This means that equation (6) can be considered to be a co-integrating equation, i.e. one which describes the long-term equilibrium between the $X_{t}$ and $Y_{t}$ processes.

The proposed procedure allows one to gauge the direction and dynamics of change and facilitates the detection of possible convergence in the exportoriented and import-oriented process of intra-industry trade specialisation.

\section{FINDINGS}

Analysing the course of the time series of variances of the export-oriented and import-oriented indicators computed on an annual basis for industries with varying degrees of technological advancement, the author decided to model them using the quadratic trend function (5). The author's choice of the function was dictated by the statistical significance of the estimated model's parameters and its relatively stronger fit to the empirical data than that of other types of the trend function. Table 2 presents an estimation of the quadratic trend function parameters computed for indicators of export-oriented and import-oriented intensity of foreign trade in each of the four selected sectors of the economy. In parentheses the reader will find the $p$-value, and the last column of the table contains the coefficients of determination.

Based on Table 2, it can be concluded that the estimated models of the trend reveal at least a good fit to the empirical data, and their parameters are generally statistically significant. In order to describe the development trends of the studied phenomenon, the author has also calculated the theoretical value of the peak of each parabola represented by a quadratic trend function on the horizontal axis.

Analysis of the signs of parameter $\alpha_{2}$ and the location of the peak of the parabola on the timeline indicates that, in the case of both low-tech industries and as medium low-tech industries, variances of import-oriented and export-oriented foreign trade indicators kept declining for most of the period under review. On the other hand, medium-high tech and high-tech industries show mainly a steady increase in variances $S_{a_{i}}^{2}$ and $S_{b_{i}}^{2}$ throughout the whole period (a decline in the variance of export-oriented indicators was revealed only in the HTIm variable). 
Table 2

Parameter estimates in the parabolic trend model for a variance of export-oriented and import-oriented indicators by industry (with a varying degree of technological advancement)

\begin{tabular}{|c|c|c|c|c|c|c|}
\hline \multirow{2}{*}{ Industry } & \multirow{2}{*}{ Trade direction } & \multirow{2}{*}{ Symbol } & \multicolumn{3}{|c|}{ Parameter estimates } & \multirow{2}{*}{$\mathbf{R}^{2}$} \\
\hline & & & $\mathbf{a}_{0}$ & $\mathbf{a}_{1}$ & $\mathbf{a}_{2}$ & \\
\hline \multirow{2}{*}{ low-tech (LT) } & Export & LTEx & $\begin{array}{r}0.8878 \\
(0.0000)\end{array}$ & $\begin{array}{l}-0.1476 \\
(0.0002)\end{array}$ & $\begin{array}{r}0.0088 \\
(0.0006)\end{array}$ & 0.8026 \\
\hline & Import & LTIm & $\begin{array}{r}0.5365 \\
(0.0000) \\
\end{array}$ & $\begin{array}{l}-0.0865 \\
(0.0051)\end{array}$ & $\begin{array}{r}0.0046 \\
(0.0211)\end{array}$ & 0.7970 \\
\hline \multirow{2}{*}{$\begin{array}{l}\text { medium-low- } \\
\text { tech (MLT) }\end{array}$} & Export & MLTEx & $\begin{array}{r}0.7841 \\
(0.0000) \\
\end{array}$ & $\begin{array}{l}-0.0579 \\
(0.1459) \\
\end{array}$ & $\begin{array}{r}0.0028 \\
(0.0011) \\
\end{array}$ & 0.7828 \\
\hline & Import & MLTIm & $\begin{array}{r}0.5074 \\
(0.0000) \\
\end{array}$ & $\begin{array}{l}-0.0987 \\
(0.0678) \\
\end{array}$ & $\begin{array}{r}0.0022 \\
(0.0169) \\
\end{array}$ & 0.6602 \\
\hline \multirow{2}{*}{$\begin{array}{l}\text { medium-high- } \\
\text { tech (MHT) }\end{array}$} & Export & MHTEx & $\begin{array}{r}0.2071 \\
(0.0044) \\
\end{array}$ & $\begin{array}{r}0.0152 \\
(0.4319) \\
\end{array}$ & $\begin{array}{l}-0.0005 \\
(0.1294)\end{array}$ & 0.6523 \\
\hline & Import & MHTIm & $\begin{array}{r}0.0679 \\
(0.0028) \\
\end{array}$ & $\begin{array}{r}0.0202 \\
(0.0993)\end{array}$ & $\begin{array}{l}-0.0007 \\
(0.0144)\end{array}$ & 0.5432 \\
\hline \multirow{2}{*}{ high-tech (HT) } & Export & HTEx & $\begin{array}{r}0.3232 \\
(0.4049)\end{array}$ & $\begin{array}{l}-0.0400 \\
(0.0253)\end{array}$ & $\begin{array}{l}-0.0011 \\
(0.0531)\end{array}$ & 0.4204 \\
\hline & Import & HTIm & $\begin{array}{r}0.0699 \\
(0.0044)\end{array}$ & $\begin{array}{r}0.0053 \\
(0.0297)\end{array}$ & $\begin{array}{l}-0.0004 \\
(0.0878)\end{array}$ & 0.4341 \\
\hline
\end{tabular}

Sources: author's own research based on Eurostat data.

Relying on the absolute value of parameter $\alpha_{2}$, one can also compare the speed of change in the intensity of intra-industry trade in various industries. The strongest change dynamics was noted in the variance time series of the two types of indicators in the low-tech industry. On the other hand, the variance values of import-oriented indicators in high-tech industries and export-oriented indicators in medium-high tech industries changed most slowly. It should be noted that parameter $\alpha_{2}$ in models describing variables HTIm and MHTEx is not statistically significant (at the significance level of 0.05 ), and therefore the conclusions relating to the dynamics of the change in these variables should be viewed with some caution.

In most of the industries under analysis, one can see a similarity between the nature and dynamics of change in the time series of export-oriented and import-oriented indicator variance. A more detailed analysis of the course of monthly time series of both types of these indicators suggests the possibility of their cointegration. Figures 2 and 3 plot sample time series with monthly frequency data for the low-tech industry. The examination of cointegration will help draw conclusions about the convergence of import-oriented and export-oriented specialisation of intra-industry trade in each industry. In order to test the cointegration of the time series the author has used the Engle-Granger procedure (1987). 


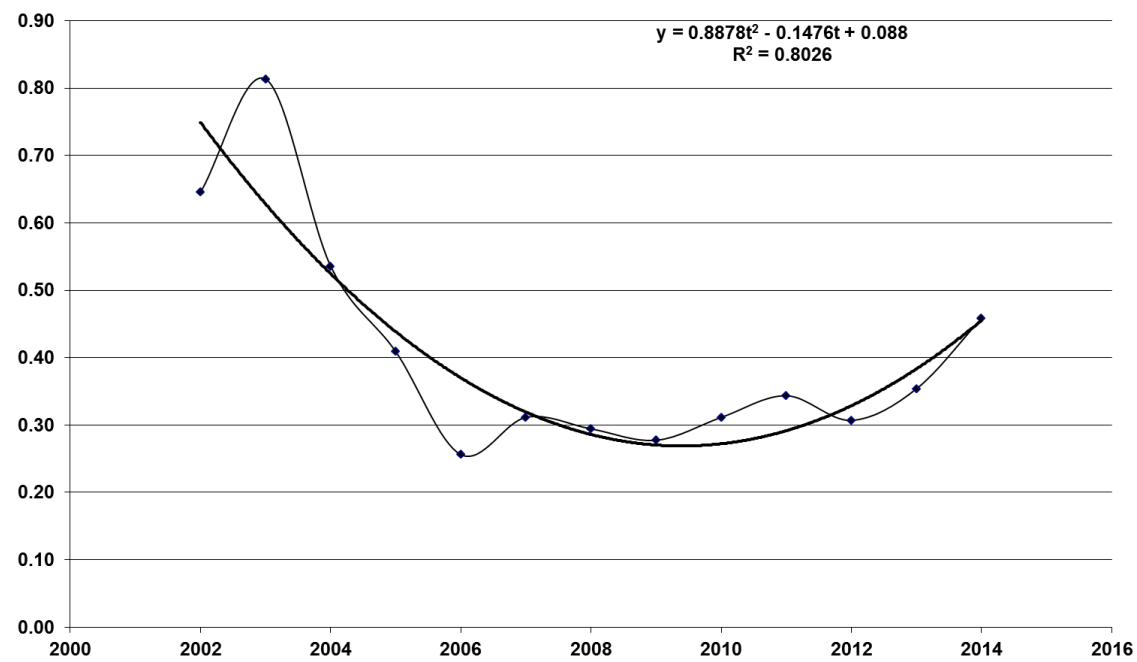

Figure 1. Time series of the variances of export-oriented indicators with annual data in the low-tech industry (LTEx) and the fitted parabolic trend

Sources: author's own research based on Eurostat data.

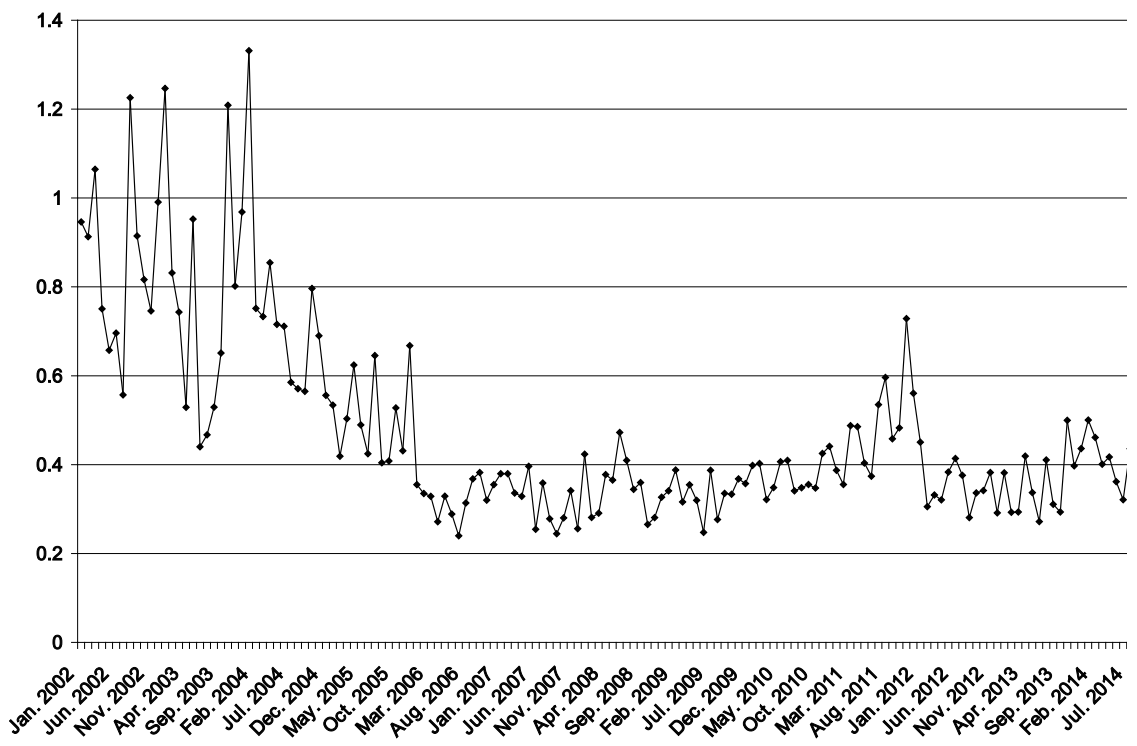

Figure 2. Time series of the variances of export-oriented indicators with monthly data in the low-tech industry (LTEx)

Sources: author's own research based on Eurostat data. 


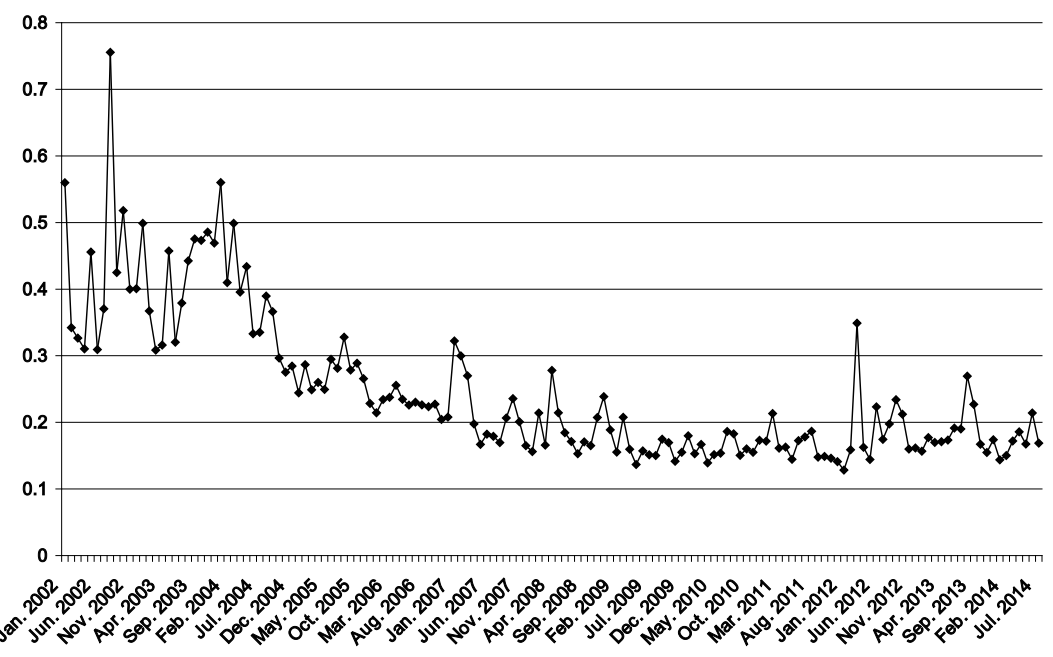

Figure 3. Time series of the variances of import-oriented indicators with monthly data in the low-tech industry (LTIm)

Sources: author's own research based on Eurostat data.

First the author has examined the integration order of the time series in each of the four industries. The results of the Dickey-Fuller test or of the augmented Dickey-Fuller test (in the event of autocorrelation) are presented in Table 3. The Durbin Watson test has been used to determine whether autocorrelation occurs in the time series or not.

\section{Table 3}

Results of studies of time series integration of intra-trade intensity indicators in industries with varying degrees of technological advancement

\begin{tabular}{l|l|l|r|r|r|r|r}
\hline \multirow{2}{*}{ Industry } & \multirow{2}{*}{$\begin{array}{c}\text { Trade } \\
\text { direction }\end{array}$} & \multirow{2}{*}{ Symbol } & \multicolumn{2}{|c|}{$\begin{array}{c}\text { Original } \\
\text { variable }\end{array}$} & \multicolumn{2}{c|}{$\begin{array}{c}\text { First } \\
\text { differences }\end{array}$} & $\begin{array}{c}\text { Integration } \\
\text { order }\end{array}$ \\
\cline { 3 - 8 } & & DF $^{*}$ (ADF) & \multicolumn{1}{c|}{ DW } & DF (ADF) & \multicolumn{1}{c|}{ DW } & \\
\hline \multirow{2}{*}{ low-tech } & export & LTEx & -1.0499 & 1.8023 & -3.3267 & 1.9674 & 1 \\
\cline { 2 - 8 } & import & LTIm & -1.3337 & 1.9345 & -5.2459 & 1.9765 & 1 \\
\hline \multirow{2}{*}{$\begin{array}{l}\text { medium- } \\
\text { low-tech }\end{array}$} & export & MLTEx & -0.9835 & 1.0032 & -5.1721 & 1.4432 & 1 \\
\cline { 2 - 8 } $\begin{array}{l}\text { medium- } \\
\text { high-tech }\end{array}$ & import & MLTIm & -1.3703 & 1.8043 & -3.8870 & 1.9645 & 1.9363 \\
\hline \multirow{2}{*}{ high-tech } & MHTEx & -2.3143 & 1.76631 & -10.105 & 1.9363 & 0 \\
\hline & import & MHTIm & -0.2482 & 1.4224 & -4.1159 & 1.5192 & 0 \\
\hline
\end{tabular}

Notes: * The critical value of DF statistic for a significance level of 0.05 is -1.94 (Davidson, MacKinnon, 1993); ${ }^{* *}$ The critical value of DW statistic is $d_{l}=1.65, d_{u}=1.69$

Source: author's own research based on data from Eurostat. 
Table 3 reveals that the test of the degree of integration of the time series of variables MLTEx, MHTIm and HTIm indicates a significant first order autocorrelation of residuals (DW statistics are smaller than the critical value $d_{l}$, both for the original variables and their first differences) in which cases the ADF test has been used, otherwise the DF test has been used. The results of both tests indicate that the time series of variables MHTEx, HTEx and HTIm are stationary, i.e. integrated of order 0 . For all the other variables only the series with first differences are stationary. Thus the time series of variables LTEx, LTIm, MLTEx, MLTIm and MHTIm are first-order integrated. Subsequently, for each industry the author has estimated a longterm equation (4), in which a variable representing import-oriented indicators $^{5}$ is the dependent variable, and a variable representing exportoriented indicators is the explanatory variable and later examined the order of integration of each model's residuals. The corresponding results are shown in Table 4. Most of the parameters in the estimated models are statistically significant and the coefficients of determination indicate a good or average fit of the models to empirical data. Based on the results of the DW test, one can conclude that residuals' autocorrelation occurred only in the model designed for the medium high-tech industry. Consequently in this case, in a bid test the order of integration of the residuals, the author has used the ADF test, and for the other industries - the DF test. The residuals have turned out to be stationary, i.e. integrated of order 0 for models built for the low-tech, medium low-tech and high-tech industries. In the medium-high tech industry, the residuals of the model (4) are integrated of order one (1).

Table 4

Testing the degree of residuals integration in a long-term equation

\begin{tabular}{|c|c|c|c|c|c|c|c|}
\hline \multirow{2}{*}{ Industry } & \multicolumn{2}{|c|}{$\begin{array}{c}\text { Parameter estimates } \\
\text { of equation }\end{array}$} & \multirow{2}{*}{$\mathbf{R}^{2}$} & \multirow{2}{*}{ DW } & \multirow{2}{*}{$\begin{array}{c}\text { DF, ADF } \\
\text { test results } \\
\text { for residuals }\end{array}$} & \multirow{2}{*}{$\begin{array}{l}\text { DF, ADF } \\
\text { test results } \\
\text { for first } \\
\text { differences }\end{array}$} & \multirow{2}{*}{$\begin{array}{c}\text { Residuals } \\
\text { integration } \\
\text { order }\end{array}$} \\
\hline & $\mathbf{b}_{0}$ & $\mathbf{b}_{1}$ & & & & & \\
\hline low-tech & $\begin{array}{r}0.0593 \\
(0.0000)\end{array}$ & $\begin{array}{r}0.3907 \\
(0.0000) \\
\end{array}$ & 0.8361 & 1.8038 & -3.0799 & -4.6892 & 0 \\
\hline $\begin{array}{l}\text { medium- } \\
\text { low-tech }\end{array}$ & $\begin{array}{r}0.2626 \\
(0.0000)\end{array}$ & $\begin{array}{r}0.1378 \\
(0.0018) \\
\end{array}$ & 0.7483 & 1.9233 & -2.1958 & -4.3605 & 0 \\
\hline $\begin{array}{l}\text { medium- } \\
\text { high-tech }\end{array}$ & $\begin{array}{r}0.1474 \\
(0.0000)\end{array}$ & $\begin{array}{r}0.1396 \\
(0.0026) \\
\end{array}$ & 0.5620 & 0.7989 & -1.2005 & -2.9477 & 1 \\
\hline high-tech & $\begin{array}{r}0.1143 \\
(0.0000)\end{array}$ & $\begin{array}{r}0.0423 \\
(0.1769)\end{array}$ & 0.4104 & 2.1530 & -3.8084 & -5.0747 & 0 \\
\hline
\end{tabular}

Source: author's own research based on data from Eurostat.

\footnotetext{
${ }^{5}$ The direction of the interaction between the variables has been determined in keeping with the assumption that imports of foods can be financed by exports.
} 
By combining the results of the integration of the time series of exportoriented and import-oriented indicators in the various industries with the results of the integration of model (4) residuals, it can be concluded that time series cointegration occurs in low-tech and medium low-tech industries. Thus, one can see convergence of export-oriented and import-oriented processes of intensification of inter-industry trade in these industries. In the other industries the time series are not integrated and export-oriented and import-oriented processes are divergent, so the equations computed in the medium high-tech and high-tech industries are not cointegrated.

\section{CONCLUSIONS}

The results of the studies indicate that Poland's low-tech and medium low-tech industries are dominated by a falling trend relating to exportoriented and import-oriented indicators, accompanied by the cointegration of the corresponding time series of these indicators. In addition, the intensity of change in these indicators in these industries is higher than in the high-tech and medium-high tech industries. This may be indicative of the relatively rapid process of the growing specialisation of intra-industry trade in the lowtech and medium low- tech industries. In the medium-high tech and hightech industries, a growth trend predominates but no cointegration has been detected between both types of indicators. This implies a trend of declining intra-industry trade specialisation in these industries, and consequently a worsening of the international competitiveness of the economy in terms of goods which are at least medium-tech. In addition the lack of cointegration in the medium high-tech and high-tech industries indicates that change processes in international competitiveness in each of these two industries in the domestic market follow a course which is different from that in the foreign markets.

The final conclusion to be drawn from the research into the intensity of intra-industry trade for the Polish economy is therefore moderately optimistic: Poland's economy has a growing ability to sell goods which are only slightly advanced technologically, whereas its competitiveness in terms of the sale of hi-tech goods is poor. The research results as presented in the paper should be viewed with caution due to the limitations of the Glejser, Goossens and van den Eede method itself. The main drawbacks of this procedure involve its failure to take into account the internal structure of intra-industry trade and its poor ability to reflect the structural changes manifest in the domestic and global economies (e.g. short-term and 
institutional changes). Despite these limitations, equipping the Glejser, Goossens and van den Eede method with tools with which to infer about the direction, dynamics of change and cointegration of the time series of variance of foreign trade intensity indicators seems to be an interesting supplement to this test procedure allowing for its wider implementation.

\section{REFERENCES}

Aquino, A., Intra-industry Trade and Inter-industry Specialization as Concurrent Sources of International Trade in Manufacturing, "Weltwirtschaftliches Archiv" 114 (2), pp. 275$-296,1978$.

Brülhart, M., Marginal Intra-Industry Trade: Measurement and Relevance for the Pattern of Industrial Adjustment, "Weltwirtschaftliches Archiv" 130 (3), pp. 600-613, 1994.

Davidson, R., MacKinnon, J. G., Estimation and Inference in Econometrics. Oxford University, New York, 1993.

Engle, F. R., Granger, C. W. J., Cointegration and Error Correction: Representation, Estimation, and Testing, "Econometrica" 55 (2), pp. 251-276, 1987.

Fontagné, L., Freudenberg, M., Péridy, N., Trade Patterns inside the Single Market, CEPII Working paper, pp. 97-07, 1997.

Glejser, H., Goossens, K., Eede van den, M., Inter Industry Versus Intra Industry Specialization in Exports and Imports (1959-1970-1973), "Journal of International Economics" 12 (3-4), pp. 363-369, 1982.

Greenaway, D., Hine, R., Milner, C., Vertical and Horizontal Intra-Industry Trade: A CrossIndustry Analysis for the United Kingdom, "Economic Journal" 105, pp. 1505-1519, 1995.

Grubel, H. G., Lloyd, P. J., Intra-Industry Trade: The Theory and Measurement of International Trade in Differentiated Products. McMillan, New York, 1975.

Hatzichronoglou, T., Revision of the High-Technology Sector and Product Classification, OECD Science, Technology and Industry Working Papers 1997/02, OECD Publishing, Paris, 1997.

Johansen, S., Estimation and Hypothesis Testing of Cointegration Vectors in Gaussian Vector Autoregressive Models, "Econometrica" 59 (6), pp. 1551-1581, 1991.

Johansen, S., Determination of Cointegration Rank in the Presence of a Linear Trend, "Oxford Bulletin of Economics and Statistics" 54 (3), pp. 383-397, 1992.

Osińska, M., Kośko, M., Stempińska, J., Ekonometria wspótczesna [Modern Economy], „Dom Organizatora", Toruń, 2007.

Zeliaś, A., Steczkowski, J., Woźniak, M., Zając, K., Statystyka matematyczna w zastosowaniach [Using of Mathematic Statistics], Cracow university of Economic Publishing House, Cracow, 1996.

Received: May 2015, revised: March 2017 